\title{
A Dual Band Additively Manufactured 3D Antenna on Package with Near-Isotropic Radiation Pattern
}

\author{
Zhen Su, Student Member, IEEE, Kirill Klionovski, Rana Muhammad Bilal and Atif Shamim, Senior \\ Member, IEEE
}

\begin{abstract}
Internet of things (IoT) applications need wireless connectivity on devices with very small footprints, and in RF obscure environments. The antenna for such applications must work on multiple GSM bands (preferred choice for network connectivity), provide near isotropic radiation pattern to maintain orientation insensitive communication, be small in size so that it can be integrated with futuristic miniaturized IoT devices, and be low in cost to be implemented on billions of devices. This paper presents a novel 3D dual band near-isotropic wideband GSM antenna to fulfill these requirements. The antenna has been realized on the package of electronics through additive manufacturing to ensure efficient utilization of available space and lower cost. The proposed antenna consists of a meander line antenna that is folded on the faces of a 3D package with two variations, $0.375 \lambda$ length for narrowband version and $0.67 \lambda$ length for the wideband version. Theoretical conditions to achieve near isotropic radiation pattern with bent wire antennas on a $3 D$ surface have been derived. The antenna has been optimized to operate with embedded electronics and a large metallic battery. The antenna provides $8.9 \%$ and $34.4 \%$ bandwidths, at 900 and $1800 \mathrm{MHz}$ respectively with decent near isotropic radiation behavior.
\end{abstract}

Index Terms - Dual-band antennas, wideband antennas, antennas on package, additive manufactured antenna, quasi-isotropic radiation pattern

\section{INTRODUCTION}

$\mathrm{I}$ nternet of Things (IoT) is a paradigm where billions of devices, embedded in everyday objects such as dishwasher, coffeemaker, cabinets etc. are connected to the internet for smart applications [1-3]. Very often than not, these devices use GSM band for connectivity [4][5]. This is because, GSM has a preinstalled global telecommunication infrastructure. Thus, designers can design devices capable of sending and receiving data from anywhere in the world, without worrying about infrastructure installment for individual applications. GSM has four different frequency bands that are being used in various regions of the world. GSM900 and GSM1800 bands are used in

Manuscript received $30^{\text {th }}$ Sept 2017.

Zhen Su, Kirill Klionovski, Rana Muhammad Bilal and Atif Shamim are with the Department of Electrical Engineering, King Abdullah University of Science and Technology, Thuwal 23955-6900, Saudi Arabia (e-mail: su.zhen@kaust.edu.sa)
Europe, Middle East, Africa and Asia Pacific region. GSM900 band has 8.7\% bandwidth (Uplink MHz: 880.0 - 915.0, Downlink MHz: 925.0 - 960.0). Whilst GSM1800 band has 9.45\% bandwidth (Uplink MHz: 1710.2 - 1784.8, Downlink MHz: 1805.2 - 1879.8) [6]. As can be noticed, both bands have fairly wide bandwidth requirements. For region limited applications it is usually sufficient to cover only the respective regional GSM band. However, covering more GSM bands is attractive for IoT devices, as it ensures that device will be able to function in more countries around the globe. GSM is a well-established communication standard for urban environments and GSM enabled IoT devices are often placed inside the buildings, or crowded environments. In such setting, devices may have proper GSM signal strength available only in certain single direction. Thus, an isotropic or near-isotropic radiation pattern on an IoT device antenna is desirable to ensure that the device is able to function properly irrespective of its placement orientation. IoT devices are exponentially increasing in number and are expected to exceed 20 billion by 2020 [7]. With such large number of devices, cost is a very important consideration whilst designing new devices. Also, with newer applications demanding IoT capability on small items, there is an increasing pressure for designs to be miniaturized. Summarizing the above discussion from antenna design perspective, it can be seen that space efficient, low cost, multiband near-isotropic GSM antennas, with sufficiently wide bandwidth have critical value in design of new IoT devices.

Miniaturization and lower cost can be addressed through Antenna-on-Package (AoP) concept and by utilizing additive manufacturing techniques [8-11]. AoP concept is useful because the antenna is integrated on the package of the chip or the device. Since packaging is already present on every electronic device, fabricating the antenna on it saves any additional requirement of space and material and thus makes it economical. Further cost savings can be done through additive manufacturing techniques such as 3D printing, Inkjet printing etc, as these methods are digital and thus do not require expensive masks. Moreover, they deposit material only where required as compared to the traditional subtractive manufacturing techniques where pattern is realized by removing material. Thus, material wastage and cost is reduced.

Unfortunately, however there is no prior work in research literature that makes use of these recent techniques to combine 


\begin{tabular}{|c|c|c|c|c|c|c|c|c|}
\hline \multicolumn{9}{|c|}{$\begin{array}{c}\text { TABLE I } \\
\text { Comparison of Near Isotropic Antennas }\end{array}$} \\
\hline Paper & $\begin{array}{c}\text { Antenna Type } \\
\text { (Isotropicity strategy) }\end{array}$ & AoP & $2 \mathrm{D}$ or $3 \mathrm{D}$ & $\begin{array}{c}\text { Additive } \\
\text { manufacturing }\end{array}$ & $\begin{array}{l}\text { Electrical } \\
\text { length }(\lambda)^{*}\end{array}$ & $\begin{array}{l}\text { Dual } \\
\text { Band }\end{array}$ & $\begin{array}{l}\text { Bandwidth } \\
(\%)\end{array}$ & $\begin{array}{r}\text { Gain } \\
(\mathrm{dBi})\end{array}$ \\
\hline$[12]$ & $\begin{array}{l}\text { Bended dipole with a double } \\
\text { T-matching network; } \\
\text { (Electric with magnetic dipole) }\end{array}$ & NO & $2 \mathrm{D}$ & NO & 1.17 & NO & 8.5 & NA \\
\hline$[13]$ & $\begin{array}{c}\text { Bended dipole with } \\
\text { inductively coupled feeding; } \\
\text { (Electric with magnetic dipole) }\end{array}$ & NO & $2 \mathrm{D}$ & NO & 0.98 & NO & 1 & -0.04 \\
\hline$[14]$ & $\begin{array}{c}\text { A symmetric inverted-F } \\
\text { structure with a bent section; } \\
\text { (Electric with magnetic dipole) }\end{array}$ & NO & $2 \mathrm{D}$ & NO & 0.65 & NO & 3.2 & NA \\
\hline$[15]$ & $\begin{array}{c}\text { Two orthogonal electric } \\
\text { dipoles } \\
\text { (Electric dipoles) }\end{array}$ & NO & $2 \mathrm{D}$ & NO & 0.7 & NO & 11 & 1.51 \\
\hline$[16]$ & $\begin{array}{l}\text { Four L-shaped monopoles fed } \\
\text { by a sequential 90deg phase } \\
\text { feeding network } \\
\text { (Electric dipoles) }\end{array}$ & NO & $2 \mathrm{D}$ & NO & 1 & NO & 20.82 & 2 \\
\hline$[17]$ & $\begin{array}{l}\text { Dielectric resonator antenna } \\
\text { (Electric with magnetic dipole) }\end{array}$ & NO & $3 \mathrm{D}$ & NO & NA & NO & 7.3 & 3.7 \\
\hline$[18]$ & $\begin{array}{l}\text { Folded split-ring resonators } \\
\text { (Electric with magnetic dipole) }\end{array}$ & NO & $3 \mathrm{D}$ & NO & 0.81 & NO & 1.8 & 2.12 \\
\hline$[19]$ & $\begin{array}{l}\text { Folded on the sphere } \\
\text { (Electric dipoles) }\end{array}$ & NO & $3 \mathrm{D}$ & NO & 0.65 & NO & 0.77 & 0.75 \\
\hline$[20]$ & $\begin{array}{c}\text { Meander wire dipole folded on } \\
\text { the cube } \\
\text { (Electric dipole) }\end{array}$ & YES & $3 \mathrm{D}$ & YES & 1.36 & NO & 1.3 & 0.53 \\
\hline$[21]$ & $\begin{array}{c}\text { Meander wire dipole folded on } \\
\text { the cube } \\
\text { (Electric dipoles) }\end{array}$ & YES & $3 \mathrm{D}$ & YES & 1.5 & NO & NA & -1 \\
\hline$[22]$ & $\begin{array}{l}\text { U-shape folded slot antenna } \\
\text { (Electric with magnetic dipole) }\end{array}$ & NO & $3 \mathrm{D}$ & NO & 0.96 & NO & 1.125 & 1.7 \\
\hline \multirow{2}{*}[24]{} & \multirow{2}{*}{$\begin{array}{l}\text { Special electric and magnetic } \\
\text { dipole pair; slots loading } \\
\text { (Electric with magnetic dipole) }\end{array}$} & \multirow{2}{*}{ NO } & \multirow{2}{*}{$3 \mathrm{D}$} & \multirow{2}{*}{ NO } & \multirow{2}{*}{0.73} & $792 \mathrm{MHz}$ & 2.8 & 1.8 \\
\hline & & & & & & $1214 \mathrm{MHz}$ & 1.8 & 2.33 \\
\hline \multirow{2}{*}{$\begin{array}{l}\text { This } \\
\text { work }\end{array}$} & \multirow{2}{*}{$\begin{array}{l}\text { Meander antenna folded on } \\
\text { rectangular box } \\
\text { (Electric dipoles) }\end{array}$} & \multirow{2}{*}{ YES } & \multirow{2}{*}{$3 \mathrm{D}$} & \multirow{2}{*}{ YES } & \multirow{2}{*}{0.67} & $900 \mathrm{MHz}$ & 8.9 & 0.9 \\
\hline & & & & & & $1.8 \mathrm{GHz}$ & 33.3 & 1.7 \\
\hline
\end{tabular}

* The electrical length in fractions of wavelength $(\lambda)$ for an antenna has been calculated for the lowest operating frequency.

desired antenna qualities for IoT devices discussed above, in a single antenna. Table 1 shows a comparison of various research works targeting near isotropic antenna designs. As can be seen that there are very few works that employ AoP and/or additive manufacturing concepts. Further, the works such as [20][21] that do utilize AoP and additive manufacturing concepts for miniaturization and cost reduction, are single narrow band only. This is because maintaining near isotropic radiation pattern, and sufficiently wide bandwidth on multiple bands is quite challenging for AoP designs. A lot of works $[12,13,14$, $17,18,22,25]$ have employed electric-magnetic dipole pair technique with $2 \mathrm{D}$ antenna design to achieve near-isotropic radiation pattern. Being 2D these designs take up a large space and are prone to lose communication link, if IoT device is placed such that antenna is close to and facing ground. Alternatively, 3D designs such as antenna presented in this paper achieve near isotropic radiation pattern by putting antenna segments on multiple faces of package. These designs are advantageous in the sense, that communication is still possible even if IoT device is placed such that one of antenna segment is close to and facing ground. Some of the works [17-24] have employed 3D antenna design approach for near isotropic radiation pattern. These works however are single band and do not have sufficiently wide bandwidths. Paper [24] has presented a 3D antenna design, which is dual band. This design is however narrow band and neither employs additive 
manufacturing nor AoP concept. Papers [25][26] have also presented interesting antenna designs, however they have not been included in table 1, because [25] is only simulations based paper and does not report any measured results. In addition, designs in both papers have nulls within a small portion of the radiation sphere, which is neglected in determining the isotropic behavior. Note, that a theoretical model of an electrical dipole and a magnetic dipole was investigated in [15] for obtaining quasi-isotropic radiation pattern of a dielectric resonator antenna. However, that model is not suitable for wire antenna on package design. Summarizing the discussion, as of yet, none of the works in recent research literature demonstrate an antenna which fulfills all the requirements for modern IoT devices. As mentioned before, this is due to design difficulties faced, whilst trying to combine all requisite features established above in a single design.

This paper presents, for the first time, a GSM dual-band bended wire antenna, fabricated on a package using additive manufacturing. Preliminary simulation results of the dual band 3D antenna have been shown in a conference paper [27]. The antenna has near isotropic radiation pattern in both GSM900 and GSM1800 bands. The antenna satisfies bandwidth requirements for both GSM bands. Moreover, this paper derives theoretical conditions for designing near isotropic wire antennas on $3 \mathrm{D}$ surfaces.

\section{THE CONDITIONS OF A NEAR-ISOTROPIC WIRE ANTENNA}

Near-Isotropic GSM dual band antenna presented in this paper is a wire antenna wrapped on the surface of a package. The radiation pattern of a wire antenna can be determined as the superposition of radiation patterns of a set of electrical dipoles. Each electric dipole is assumed to simulate a bended segment of the wire antenna. Conditions to optimize shape of the AoP for near-isotropic radiation pattern can be determined by using a model of three orthogonal electrical dipoles.

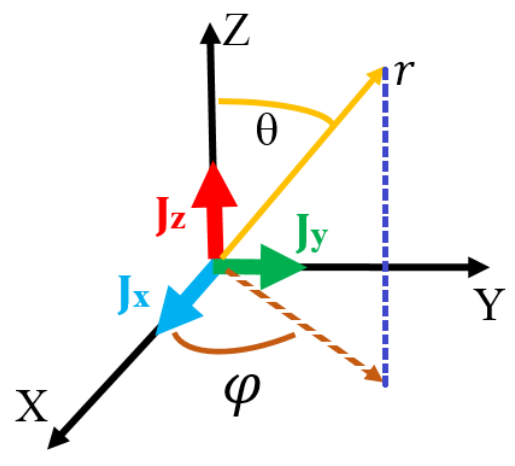

Fig. 1. X-, Y- and Z- oriented electrical dipoles.

\section{A. The Model Of Two Electric Dipoles}

Fig. 1 shows the basic model for analysis of orthogonal set of electrical dipoles. We start by investigating the electrical dipoles, located along $\mathrm{X}$ - and $\mathrm{Y}$ - axes.

The current densities of the $\mathrm{X}$ - and $\mathrm{Y}$-axes oriented electrical dipoles in the Cartesian coordinate system $(\mathrm{X}, \mathrm{Y}, \mathrm{Z})$ are given as:

$$
\begin{aligned}
& \mathbf{J}_{\mathrm{x}}(\mathrm{X}, \mathrm{Y}, Z)=m_{x} \delta(\mathrm{X}) \delta(\mathrm{Y}) \delta(\mathrm{Z}) \mathbf{x}_{0}, \\
& \mathbf{J}_{\mathrm{y}}(\mathrm{X}, \mathrm{Y}, \mathrm{Z})=m_{y} \delta(\mathrm{X}) \delta(\mathrm{Y}) \delta(\mathrm{Z}) \mathbf{y}_{0} .
\end{aligned}
$$

where $m_{\mathrm{x}}$ and $m_{\mathrm{y}}$ are the moments of the dipoles along $\mathrm{X}$ and $\mathrm{Y}$ axis respectively; $\delta(\mathrm{x})$ is the Dirac delta-function; $\mathbf{x}_{0}$ and $\mathbf{y}_{0}$ are the unit vectors along the $\mathrm{X}-$ and $\mathrm{Y}-$ axis; $\mathbf{J}_{\mathbf{x}}$ and $\mathbf{J}_{\mathbf{y}}$ are the current densities of the dipoles along the $\mathrm{X}$ - and $\mathrm{Y}$-axis. The electric dipole along $\mathrm{X}$-axis has the meridional $E_{\theta}$ and azimuthal $E_{\varphi}$ components of radiation pattern in the spherical coordinate system $(r, \theta, \varphi)$ :

$E_{\theta}(\theta, \varphi)=-j \eta \cos \theta \cos \varphi \frac{k}{4 \pi} m_{x}$,

$E_{\varphi}(\varphi)=j \eta \sin \varphi \frac{k}{4 \pi} m_{x}$.

The components of the radiation pattern of dipole along $\mathrm{Y}$-axis are:

$$
\begin{aligned}
& E_{\theta}(\theta, \varphi)=-j \eta \cos \theta \sin \varphi \frac{k}{4 \pi} m_{y}, \\
& E_{\varphi}(\varphi)=-j \eta \cos \varphi \frac{k}{4 \pi} m_{y} .
\end{aligned}
$$

Where $\eta=120 \pi ; \mathrm{k}=2 \pi / \lambda ; \lambda$ is free space wavelength; $j$ is the imaginary unit. A combination of the $\mathrm{X}$ - and $\mathrm{Y}$ - oriented dipoles with a phase shift $\psi$, gives meridional and azimuthal components of radiation pattern as follow:

$$
\begin{aligned}
& E_{\theta}^{\Sigma}(\theta, \varphi)=-j \eta \cos \theta \cos \varphi \frac{k}{4 \pi} m_{x}-j \eta \cos \theta \sin \varphi \frac{k e^{j \psi}}{4 \pi} m_{y}, \\
& E_{\varphi}^{\Sigma}(\varphi)=j \eta \sin \varphi \frac{k}{4 \pi} m_{x}-j \eta \cos \varphi \frac{k e^{j \psi}}{4 \pi} m_{y} .
\end{aligned}
$$

Phase difference $\psi$ between the dipoles can be optimized, when they have the unit moments $\left(m_{x}=m_{y}=1\right)$, to get the most isotropic total radiation pattern:

$$
\left|E^{\Sigma}(\theta, \varphi)\right|^{2}=\left|E_{\theta}^{\Sigma}(\theta, \varphi)\right|^{2}+\left|E_{\varphi}^{\Sigma}(\varphi)\right|^{2} \text {. }
$$

Using (4) and (5), the expression for the total radiation pattern can be written as:

$$
\begin{aligned}
& \left|E^{\Sigma}(\theta, \varphi)\right|^{2}=\left(\eta \frac{k}{4 \pi}\right)^{2} \times \\
& \times\left(1+\cos ^{2} \theta-\sin (2 \varphi) \cos \psi+\cos ^{2} \theta \sin (2 \varphi) \cos \psi\right) . \\
& \quad \text { When } \psi=\pi / 2,(6) \text { can be simplified as: } \\
& \left|E^{\Sigma}(\theta)\right|^{2}=\left(\eta \frac{k}{4 \pi}\right)^{2}\left(1+\cos ^{2} \theta\right) .
\end{aligned}
$$

From (7) it can be seen that variation of the total radiation pattern from the maximum to minimum value is $3 \mathrm{~dB}$. At $\psi=0$, (6) can be simplified as:

$$
\left|E^{\Sigma}(\theta, \varphi)\right|^{2}=\left(\eta \frac{k}{4 \pi}\right)^{2}\left(1+\cos ^{2} \theta-\sin (2 \varphi)+\cos ^{2} \theta \sin (2 \varphi)\right) \text {. }
$$

From (8) it can be seen that the total radiation pattern has a null direction at $\theta=\pi / 2$ and $\varphi=\pi / 4,5 \pi / 4$. Thus, a quasi-isotropic radiation pattern can be achieved, when the orthogonal dipoles have a $90^{\circ}$ phase difference. Fig. 2 shows radiation pattern (6) for different $\psi$. From this figure it can be seen that the radiation pattern has $11.7,8.34$ and $6.2 \mathrm{~dB}$ gain variation when $\psi$ is $30^{\circ}$, $45^{\circ}$ and $60^{\circ}$. 


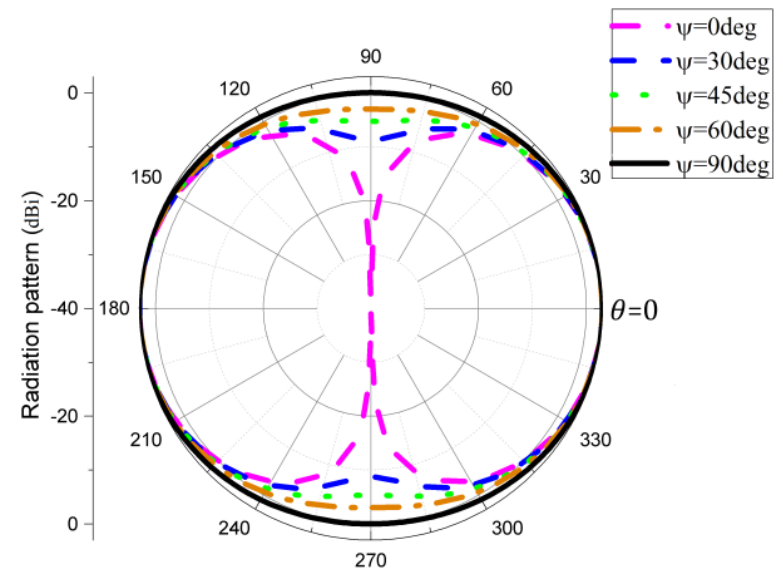

Fig. 2. Radiation patterns of the two orthogonal electric dipoles at $\varphi=\pi / 4$ plane.

\section{B. The Model Of Three Dipoles}

The two electrical dipoles model can be easily realized for a planar AoP. However, radiation efficient planar antennas are supposed to take larger space. Thus, the resulting package is not very compact. As shown in [19-21], a 3D meander antenna is composed of three or more segments covering surfaces of a package.

For the case of a 3D wire antenna that has bent segments along X-, Y- and Z-axis, the two dipoles model can be updated by adding Z-oriented dipole (Fig. 1) with current density:

$$
\mathbf{J}_{\mathrm{z}}(\mathrm{X}, \mathrm{Y}, \mathrm{Z})=m_{z} \delta(\mathrm{X}) \delta(\mathrm{Y}) \delta(\mathrm{Z}) \mathbf{z}_{0} \text {. }
$$

Where $m_{\mathrm{Z}}$ is the dipole moment and $\mathbf{z}_{0}$ is the unit vector along the Z-axis. Radiation pattern of the Z-oriented current has only meridional component:

$E_{\theta}(\theta)=j \eta \frac{k}{4 \pi} m_{z} \sin \theta$.

Total radiation pattern of the three orthogonal electrical dipoles model with unit moments $\left(m_{x}=m_{y}=m_{\mathrm{z}}=1\right)$, and a phase shift $\psi$ between X- and Y-oriented dipoles and a phase shift $\psi_{2}$ between $\mathrm{Z}$ - and $\mathrm{X}$-oriented dipoles can be written as:

$\left|E^{\Sigma}(\theta, \varphi)\right|^{2}=\left(\eta \frac{k}{4 \pi}\right)^{2}\left(2-\sin ^{2} \theta \sin (2 \varphi) \cos \psi-\right.$

$\left.-\sin (2 \theta) \cos \varphi \cos \psi_{2}-\sin (2 \theta) \sin \varphi \cos \left(\psi-\psi_{2}\right)\right)$.

When $\psi=\pi / 2$, (11) can be simplified as:

$\left|E^{\Sigma}(\theta, \varphi)\right|^{2}=\left(\eta \frac{k}{4 \pi}\right)^{2}\left(2-\sin (2 \theta) \cos \left(\varphi-\psi_{2}\right)\right)$.

From (12) it can be seen that the variation of the total radiation pattern from maximum to minimum value is $4.77 \mathrm{~dB}$ for any phase shift $\psi_{2}$. Thus, as long as the phase difference between any two dipoles (X- and Y-oriented; or Y- and Z-oriented; or X-and Z-oriented) is $90^{\circ}$, the model of the three orthogonal electrical dipoles provides near isotropic radiation pattern with $4.77 \mathrm{~dB}$ gain variation regardless of the phase of the third dipole.

\section{The Model of Three Dipoles on a Package}

The models discussed in previous sections assume that the antenna is in vacuum and the dipoles are located at the origin of the coordinate system. To analyze the concept for an antenna on a practical package, the model requires the dipoles to be placed on the faces of a dielectric package which has a cavity inside to house the circuitry and battery, as shown in Fig. 3. The dielectric package has dimensions of $\mathrm{L}=60 \mathrm{~mm}, \mathrm{~W}=43.6 \mathrm{~mm}$, $\mathrm{H}=36 \mathrm{~mm}$, and the cavity has dimension $42 \mathrm{~mm}$ alone $\mathrm{X}$ direction, $45 \mathrm{~mm}$ along $\mathrm{Y}$ direction, and $33 \mathrm{~mm}$ along $\mathrm{Z}$ direction. The material properties have been used for a typical 3D printing material "Vero Black Plus", which has a permittivity of 2.8 with a loss tangent of 0.02 at $1 \mathrm{GHz}$.

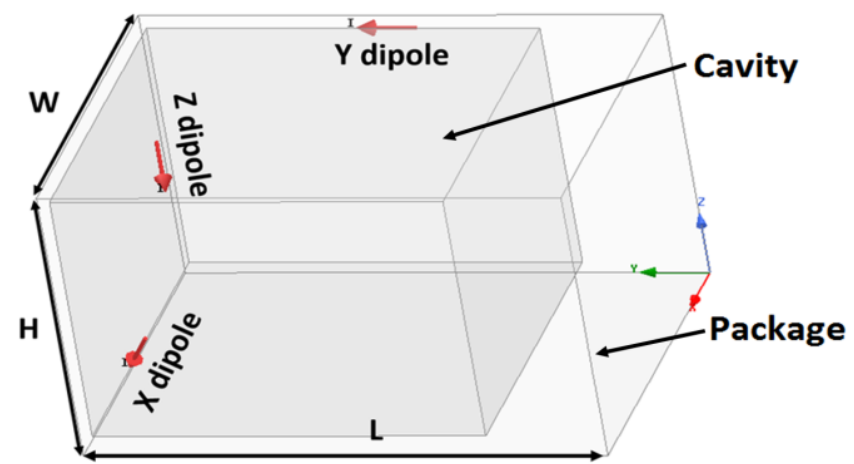

Fig. 3. The geometry of three Hertzian dipoles on a package

The dipoles are assumed to have unit moments. $\mathrm{X}$ and $\mathrm{Y}$ oriented dipoles have $0^{\circ}$ phase shift, while $\mathrm{Y}$ and $\mathrm{Z}$ oriented dipoles have $90^{\circ}$ phase shift. This model has been simulated in Ansys HFSS software. The results from HFSS simulations match well with the results from the theoretical model using (12), as can be seen in Fig. 4, where both show a gain variation

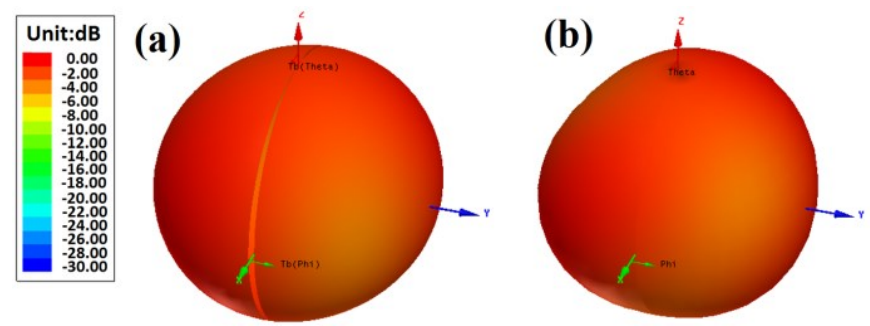

Fig. 4. 3D normalized radiation patterns of (a) the theoretical model, (b) dipoles on the package model.

of $4.7 \mathrm{dBs}$.

\section{3D Wire ANTENNA Design On A PACKAGE}

Ideal antennas have been used in the previous section to validate the near-isotropic conditions. In this section, we present a practical wire antenna design that has been wrapped on a $3 \mathrm{D}$ package.

A. The Model of Wire Antenna on a 3D Package 


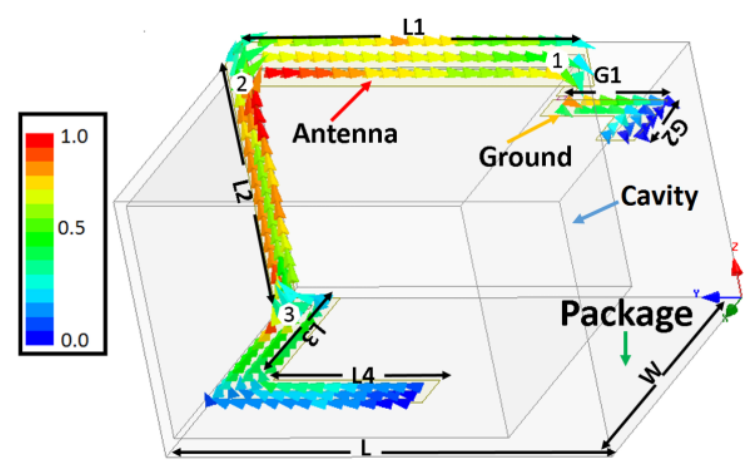

Fig. 5. The geometry of a wire AoP and the normalized current distribution on the surface of the antenna at $900 \mathrm{MHz}$.

The AoP is modeled as a meandered line structure, which is wrapped on a 3D dielectric package (Fig. 5). The dielectric package has the same dimensions as mentioned in section II C. The 3D antenna has been designed for a center frequency of $900 \mathrm{MHz}$ for single ended driving circuit connection. The wire antenna has dimensions of $\mathrm{L} 1=44 \mathrm{~mm}, \mathrm{~L} 2=36 \mathrm{~mm}, \mathrm{~L} 3=22 \mathrm{~mm}$, $\mathrm{L} 4=27.5 \mathrm{~mm}, \mathrm{~W} 1=4 \mathrm{~mm}, \mathrm{G} 1=15.5 \mathrm{~mm}, \mathrm{G} 2=6.5 \mathrm{~mm}$. The dimensions L1 and L2 have been optimized to get $90^{\circ}$ phase difference between points 1 and 2. The bending of L3 and L4 and the length of L4 effects the antenna current distribution and thus help in impedance matching. From Fig. 5 it can be seen that segments L1, L2 and L3 have areas with unit normalized current amplitude. Each of these areas can be assumed as an electrical dipole. Thus, the wire antenna shown in Fig. 5 can be approximated by three orthogonally oriented dipoles with unit amplitudes. Further, since there is $90^{\circ}$ phase difference between points 1 and 2, therefore the wire AoP must exhibit near isotropic radiation pattern (as per the conditions derived before). The maximum and minimum gain of wire AoP is $0.4 \mathrm{dBi}$ and $-5.3 \mathrm{dBi}$ respectively (gain variation of $5.7 \mathrm{~dB}$ ). The simulated 3D radiation pattern of the wire AoP for $900 \mathrm{MHz}$ center frequency is shown in Fig. 6. The gain variation is $1 \mathrm{~dB}$ more than the three orthogonal electrical dipoles at the origin,
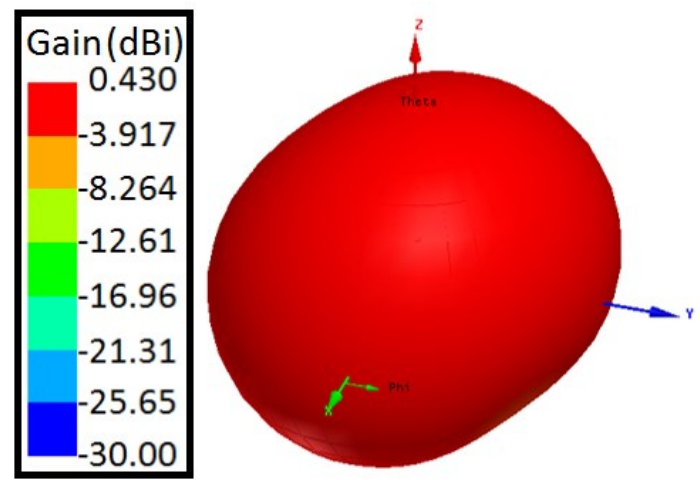

Fig. 6. The radiation pattern of the wire AoP.

however it is still good to qualify for an isotropic radiation pattern. The variation of $1 \mathrm{~dB}$ can be due to the non-idealities introduced by folding the antenna segments as well as due to the small arm used for feeding the antenna, as these are not present in the theoretical model. Nonetheless, the conditions presented in section II are good enough to design 3D wire antennas on a package with decent isotropic behavior.

\section{B. Dual-band Near Isotropic Antenna Design}

In the previous section, the mathematical conditions have been derived for achieving near isotropic radiation pattern by a wire antenna wrapped on a 3D package. This has been done for a single band and without any electronics embedded in the package. However, for practical applications, the antenna must operate for both the GSM bands ( $900 \mathrm{MHz}$ and $1800 \mathrm{MHz}$ ), as have been mentioned in the introduction section. Moreover, the antenna must operate well in the presence of electronics inside the package. In this section, we modify and optimize the antenna structure from the previous section (from Fig. 5) to accommodate for these two aspects, i.e., dual band and operation with the embedded electronics in the package. For

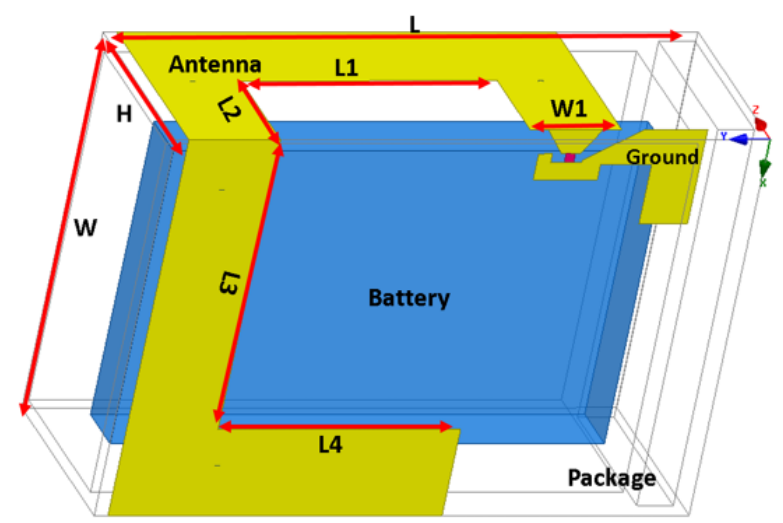

Fig. 7. The geometry of the dual band wire antenna. The antenna total length is $\mathrm{L} 1+\mathrm{L} 2 * 2+\mathrm{L} 3+\mathrm{L} 4=0.375 \lambda$.

this package, the embedded electronics is planned to be underneath the battery so it will have minimal effect on the antenna performance. However, the presence of the metallic battery will have significant effect on antenna performance so it is important to include it in the simulation model. The battery has been included as a metallic rectangular box inside the package and the size is chosen to be that of a standard BL-5C Li-Ion battery (as can be seen in Fig. 7).

To obtain the near isotropic radiation pattern at two frequency bands, designed antenna should have current distributions satisfying the theoretical condition of $90^{\circ}$ phase difference for both of the bands. For that purpose, the dimensions of the antenna and the box were optimized to get as close as possible to $90^{\circ}$ phase difference on both bands. The optimized dual band wire AoP with dimensions $\mathrm{L}=65 \mathrm{~mm}, \mathrm{~W}=$ $43.6 \mathrm{~mm}, \mathrm{H}=20 \mathrm{~mm}, \mathrm{~L} 1=28 \mathrm{~mm}, \mathrm{~L} 2=12 \mathrm{~mm}, \mathrm{~L} 3=33.6 \mathrm{~mm}$, $\mathrm{L} 4=26.5 \mathrm{~mm}, \mathrm{~W} 1=10 \mathrm{~mm}$, is shown in Fig. 7. Fig. 8 shows the simulated current distributions of the dual band antenna at 900 $\mathrm{MHz}$ and $1800 \mathrm{MHz}$. 


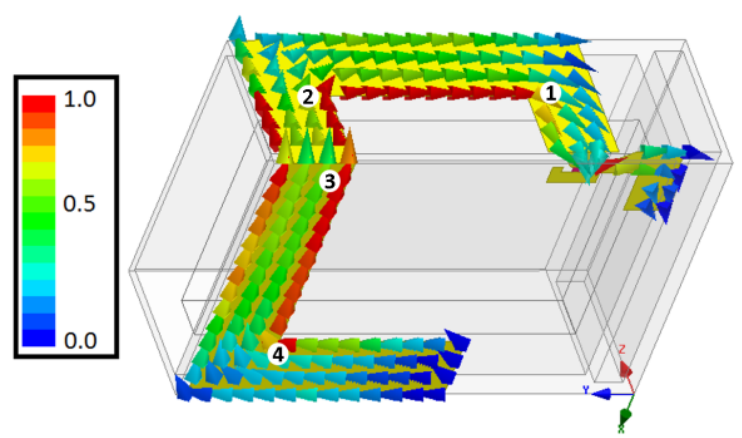

(a)

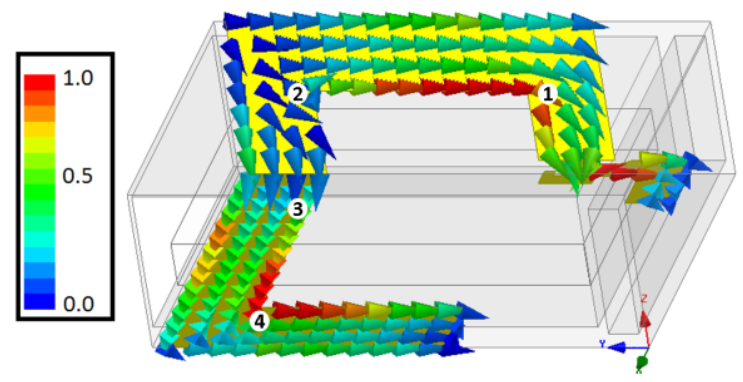

(b)

Fig. 8. The normalized current distribution on GSM dual-band antenna on package. (a) at $900 \mathrm{MHz},($ b) at $1800 \mathrm{MHz}$.

The simulated reflection coefficient $\left(\mathrm{S}_{11}\right)$ of the dual-band antenna is shown in Fig. 9. The $-10 \mathrm{~dB}$ impedance bandwidth is from $887-902 \mathrm{MHz}$ and $1780-1830 \mathrm{MHz}$, which is not sufficient to cover for the entire available GSM bandwidths. The simulated radiation patterns of the dual-band wire antenna at $900 \mathrm{MHz}$ and $1800 \mathrm{MHz}$ are illustrated in Fig. 10. At 900 $\mathrm{MHz}$, the maximum gain is $0.2 \mathrm{dBi}$ and the minimum is -5.8 $\mathrm{dBi}$ (gain variation is $6 \mathrm{~dB}$ ). At $1800 \mathrm{MHz}$, the maximum gain is $3.2 \mathrm{dBi}$ and the minimal gain is $-4.9 \mathrm{dBi}$ (gain variation is 8.1 $\mathrm{dB})$. These gain variations are acceptable for near isotropic radiation patterns.

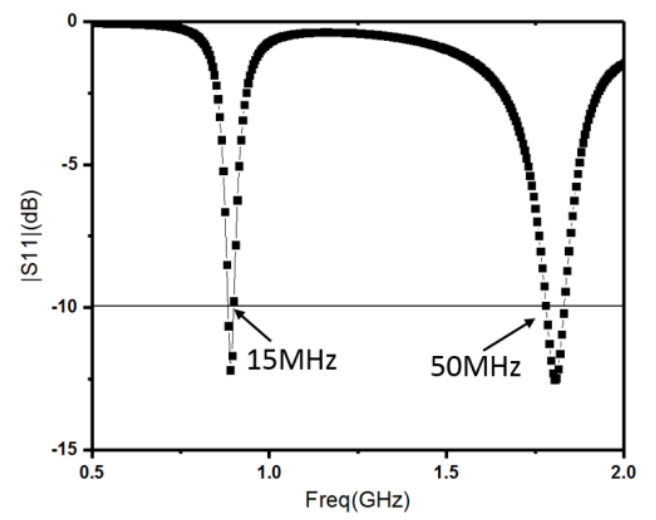

Fig. 9. Reflection coefficient of the wire dual-band antenna.

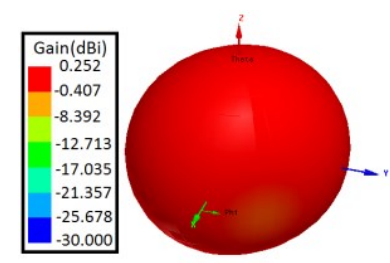

(a)
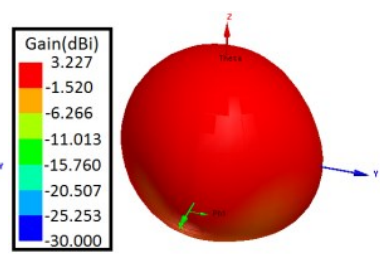

(b)
Fig. 10.3D radiation patterns of the dual-band narrow band wire antenna, (a) $900 \mathrm{MHz}$, (b) $1800 \mathrm{MHz}$.
From Fig. 8 (a) we may define three areas along X-, Y-, and Z-axis with a unit normalized current amplitude (seen with red color and marked as 1 to 2, 2 to 3 , and 3 to 4). From this simulated plot, a phase difference of $118^{\circ}$ has been recorded between points 1 and 2 at $900 \mathrm{MHz}$. The theoretical model for three dipoles predicts $6.5 \mathrm{~dB}$ gain variation when the phase difference between any two dipoles is $118^{\circ}$, where from the simulated radiation pattern it can be seen that the gain variation is $6 \mathrm{dBs}$, which is close to the predicted value from the theoretical model. From Fig. 8 (b), it can be seen that the unity normalized current only exists in the $\mathrm{X}$ and $\mathrm{Y}$ planes (areas 1 to 2 , and 3 to 4 ) with $135^{\circ}$ phase difference between points 1 and 4 at $1800 \mathrm{MHz}$. It is therefore appropriate to use the two dipoles model. The theoretical model predicts $8.3 \mathrm{~dB}$ gain variation which is quite close to the gain variation value of $8.1 \mathrm{dBs}$ from the simulated radiation pattern. Overall, a good correlation between the theoretical and simulation models can be observed.

\section{Wideband Dual-Band Near Isotropic Antenna Design}

As mentioned above, the dual-band AoP optimized in the previous section has narrow bandwidths: $1.7 \%$ at $900 \mathrm{MHz}$ and $2.8 \%$ at $1800 \mathrm{MHz}$, which cannot cover the complete GSM900 (8\% bandwidth) and GSM1800 (9.4\% bandwidth) bands. The design shown in Fig. 7 can be modified to obtain wider

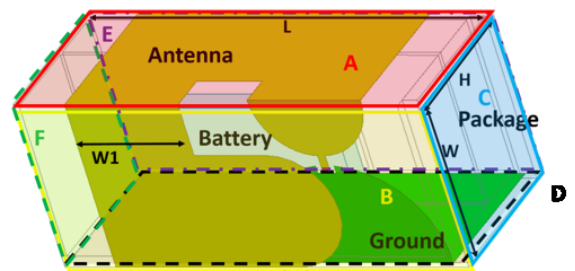

(a)

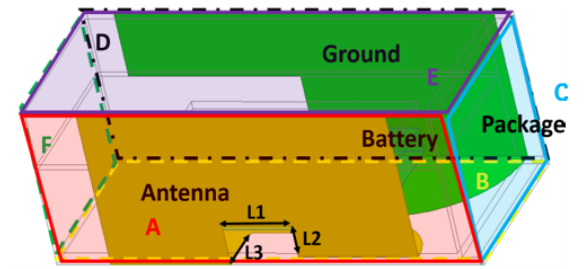

(b)

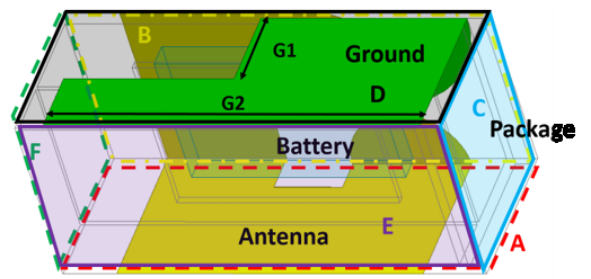

(c)

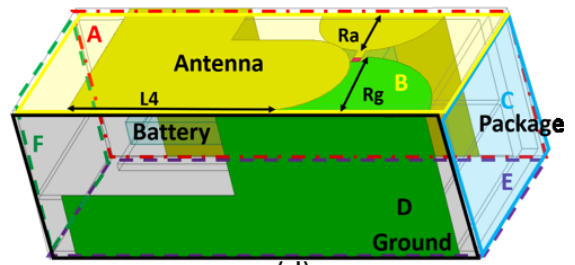

(d)

Fig. 11. Different views for the wideband dual band GSM AoP. A: the red surface; B: the yellow surface; C: the blue surface; D: the black surface opposite of A; E: the purple surface opposite of B; F: the green surface opposite of $\mathrm{C}$. The antenna length is $\mathrm{Ra} * \mathrm{pi}+\mathrm{L} 4-\mathrm{W} 1+\mathrm{L} 2 * 2+\mathrm{L} 1+\mathrm{L} 3+\mathrm{G} 1$ $+\mathrm{G} 2-2 * \operatorname{Rg}+\mathrm{Rg} *$ pi $/ 2=0.67 \lambda$ 
bandwidths. Fig. 11 shows the geometry of a wideband dual-band antenna where the total size of the package is $106.8 \times 44 \times 42 \mathrm{~mm}^{3}$ with a battery inside the package.

To obtain wider bandwidth, the width of the meander main arm has been increased and ground is enlarged as compared to the design shown in Fig. 7. As a result, the package length and height have been increased to accommodate these changes. This decreases the inductance of the line and increases the overlap between the antenna and the ground. Thus, additional capacitance is created, which reduces the quality factor Q and improves the impedance matching bandwidth. Also, the impedance matching has been improved by trimming the square edges near the excitation. The dimensions of the antenna are: $\mathrm{L}=106.8 \mathrm{~mm}, \mathrm{~W}=44 \mathrm{~mm}, \mathrm{H}=42 \mathrm{~mm}, \mathrm{Ra}=15 \mathrm{~mm}, \mathrm{Rg}=24$ $\mathrm{mm}, \mathrm{L} 1=17.3 \mathrm{~mm}, \mathrm{~L} 2=12 \mathrm{~mm}, \mathrm{~W} 1=30 \mathrm{~mm}, \mathrm{~L} 3=13.6 \mathrm{~mm}$, $\mathrm{L} 4=48.8 \mathrm{~mm}, \mathrm{G} 1=17 \mathrm{~mm}, \mathrm{G} 2=95 \mathrm{~mm}$.

The current distributions for the wideband antenna at 900 and $1800 \mathrm{MHz}$ are shown in Fig. 12 and Fig. 13. The wideband antenna has a more complex current distribution than the narrow band design due to much wider arms and complex ground plane. It can be seen in Fig. 12 that the currents at points 5 and 7, as well as points 2-3 and 6-7, have opposite directions. This is different from the previous simpler antenna design cases, where the unity amplitude (normalized) currents are not in opposite directions. Therefore, the simple theoretical model cannot accurately predict the gain variation for complex

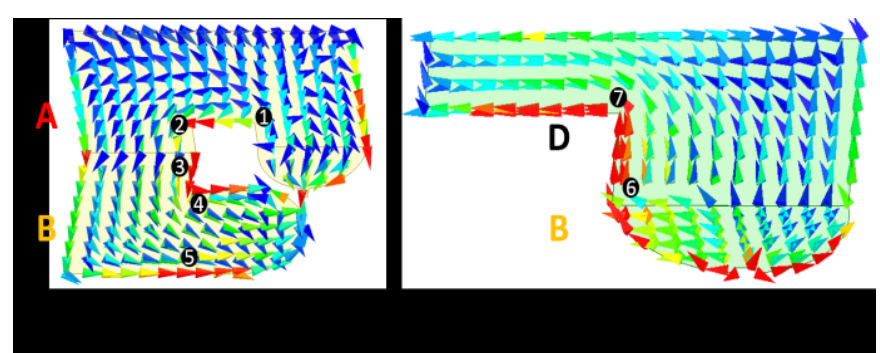

Fig. 12. The current distributions on the wideband GSM antenna at $900 \mathrm{MHz}$ : (a) current on the antenna, (b) current on the ground.

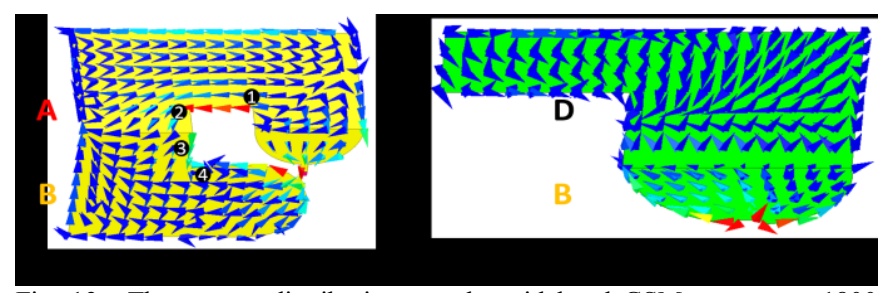

Fig. 13. The current distributions on the wideband GSM antenna at 1800 MHz: (a) current on the antenna, (b) current on the ground.

antennas such as this wide-band antenna design. Nonetheless, for complex antenna designs, it can still be used as a starting point to estimate the antenna $3 \mathrm{D}$ shape or approximate dimensions, which can then be optimized in a professional electromagnetic solver, as has been done in different iterative stages of this dual band wide band antenna design.

The simulated $S_{11}$ of the wideband dual-band antenna in comparison with the simulated $\mathrm{S}_{11}$ of the narrow band wire antenna is shown in Fig. 14. It can be seen that the $S_{11}$ of the wideband antenna is less than $-10 \mathrm{~dB}$ for frequencies ranging from $880-960 \mathrm{MHz}$ (the bandwidth is $8 \%$ ) and $1360-2250 \mathrm{MHz}$ (the bandwidth is $48.8 \%$ ). This enhancement in bandwidths at

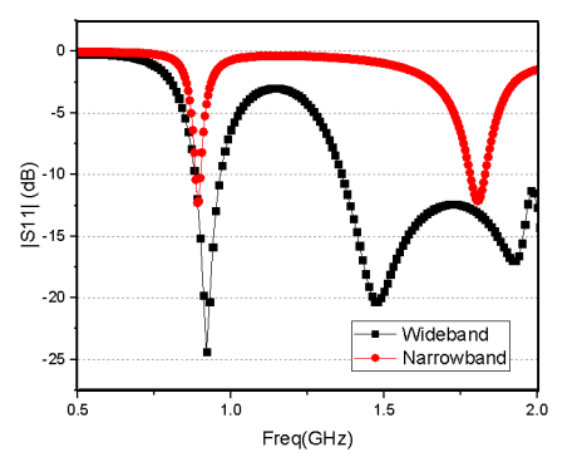

Fig. 14. Reflection coefficient of the dual-band antennas.

both the GSM bands is sufficient to cover for the entire available bandwidths.

Fig. 15 shows the normalized 2D contour radiation patterns of the wideband antenna at frequencies of $900 \mathrm{MHz}$ and 1800 MHz. The simulated maximum and minimum gains of the antenna at $900 \mathrm{MHz}$ band are $1.75 \mathrm{dBi}$ and $-7.05 \mathrm{dBi}$ respectively (the gain variation is $8.8 \mathrm{~dB}$ ). At $1800 \mathrm{MHz}$ band, the calculated maximum and minimum gain of the antenna are $3.28 \mathrm{dBi}$ and $-6.52 \mathrm{dBi}$ respectively (the gain variation is 9.8 dB). Simulations with various positions of the rectangular metallic box show that the position of battery inside package does not significantly effects the gain variation of the antenna. This is because the current on the battery's surfaces is very small. However, the positioning of the battery does strongly effects the $\mathrm{S}_{11}$ of the antenna.

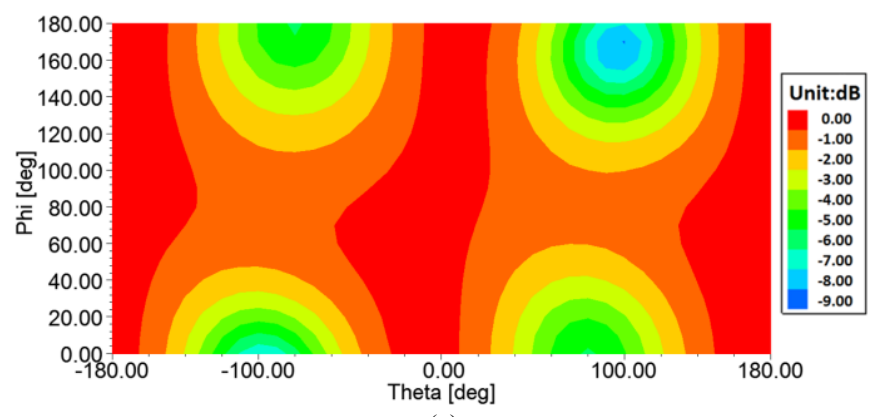

(a)

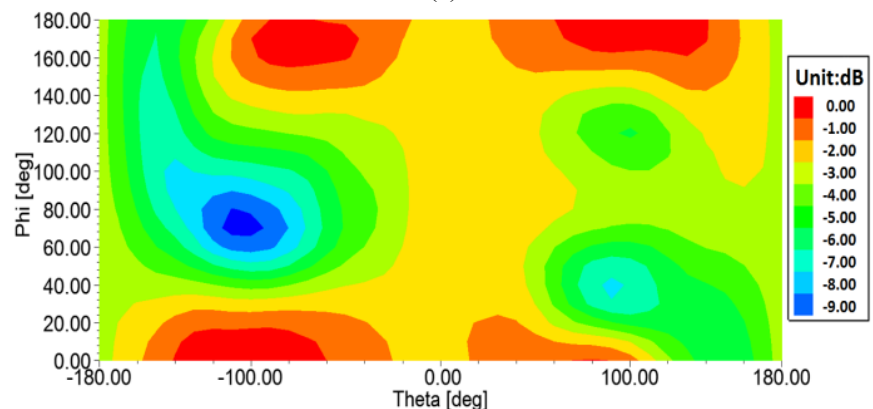

(b)

Fig. 15. Normalized radiation patterns for the wideband antenna: (a) 2D contour plot for $900 \mathrm{MHz}$ radiation pattern, (b) 2D contour plot for $1800 \mathrm{MHz}$ radiation pattern.

\section{FABRICATION AND MEASURED RESUltS}

\section{A. Fabrication}

Fabrication of AoP is challenging, since it has antenna 
segments on multiple faces of the package and some of them are on the inner faces of the 3D package. A combination of 3D printing of the dielectric material (package) and screen printing of the metal traces (antenna and ground) allowed this otherwise difficult fabrication to be done fairly easily. The package has been 3D printed in two parts (i.e. bottom base and the top box) to facilitate embedding of the battery inside the package. This step is followed by screen printing of the corresponding antenna segments on these package parts. Finally, the package parts are combined by superglue and the conductive parts are joint by conductive epoxy to realize the $3 \mathrm{D}$ printed package with integrated antenna.

The 3D printing has been done using Stratasys Objet260 Connex 1 3D printer and the process is shown in Fig. 13. This printer has 30um vertical resolution for a single layer (thickness) and maximum print dimensions of $255 \times 252 \times 200$ $\mathrm{mm}^{3}$. The material used in this printer is "Vero Black Plus" (a proprietary material from Stratasys). These values have been verified by measurements on an impedance analyzer.

In the printing process, first the package has been $3 \mathrm{D}$ printed (Fig. 16). Then, the antenna segments have been screen printed on the 3D printed package faces, using a propriety silver ink from LPKF, with a resistivity of $0.0007 \Omega-\mathrm{cm}$. Before screen printing, the $3 \mathrm{D}$ printed package surface has been cleaned and exposed to UV Ozone for a duration of $5 \mathrm{~min}$. This increases the surface adhesion of the 3D printed material. Since the 3D printed material (i.e. Vero Black Plus) deforms at temperatures above $80^{\circ} \mathrm{C}$, therefore screen-printed ink is cured at room temperature. Typically, curing at $150^{\circ} \mathrm{C}$ can take around an hour, however room temperature curing takes longer. In future, other sintering mechanisms such as photonic sintering can be used which is much localized and does not create a lot of heat or high temperature $3 \mathrm{D}$ printing materials can be explored.

Finally, the antenna segments on all the package surfaces have been connected together using Circuit Works CW2460 conductive epoxy. This epoxy has volume resistivity smaller than $0.001 \Omega-\mathrm{cm}$. The epoxy has also been cured at room

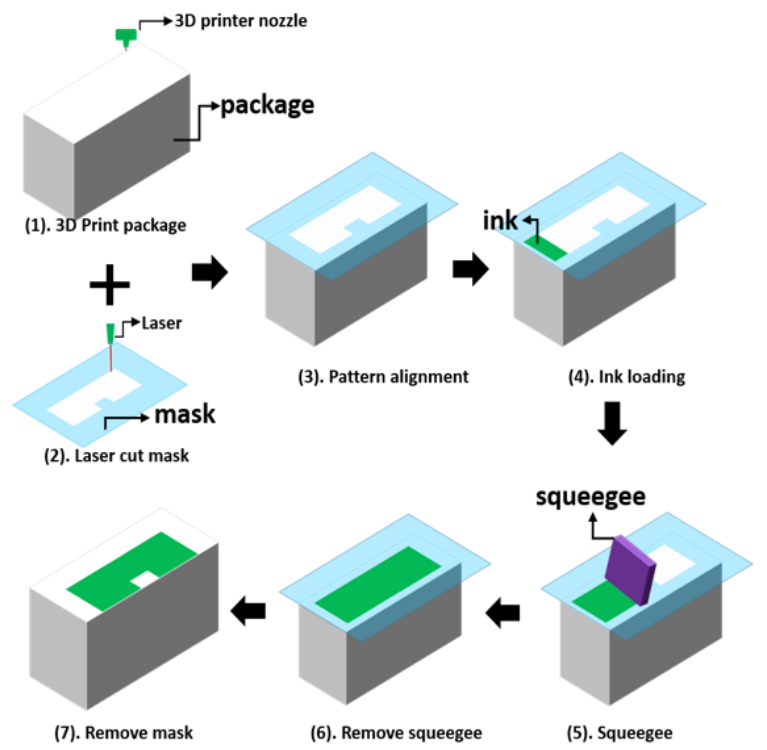

Fig. 16. Silver ink printed on the 3D printed material casing board surfaces.

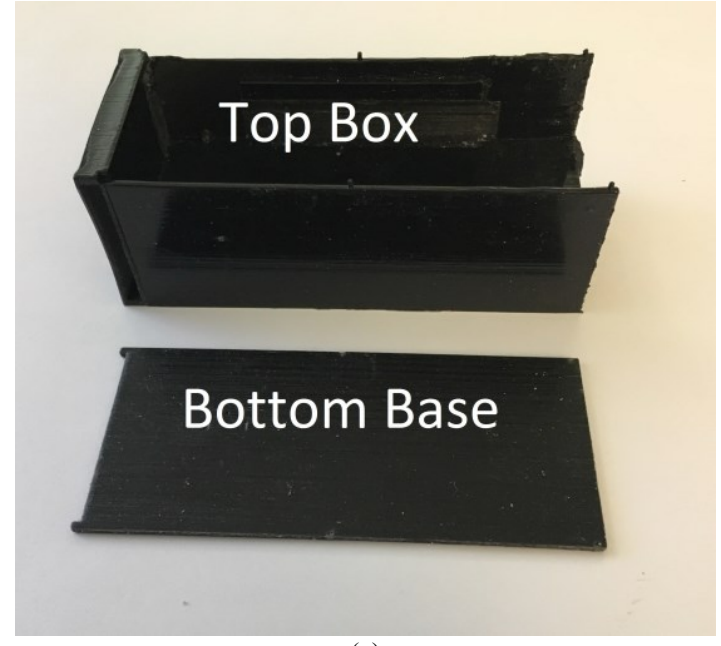

(a)

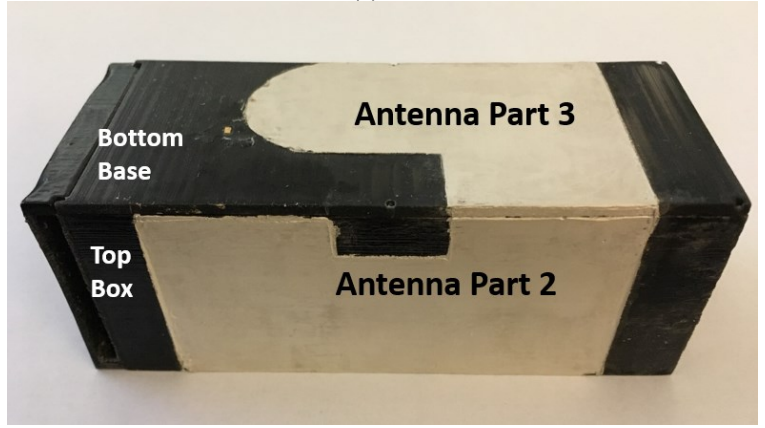

(b)

Fig. 17. (a) 3D printed top box and bottom base, (b) Printed antenna on the package.

temperature. The fully printed antenna is shown in Fig.17. It is worth mentioning here that inkjet printing of antenna segments was also tried. Though, it is possible to inkjet print conductive features at much finer resolution, inkjet printing consumes a lot of time, depending upon the drop spacing, drop volume and available nozzles. Further, multiple runs are necessary to achieve the desired thickness of the printed layers. Comparatively, screening printing can achieve few micrometers thickness in a single run; controlled by the thickness of the mask; and is much faster.

\section{B. Measurement Results}

The simulated and measured $\mathrm{S}_{11}$ of the wideband dual-band antenna are shown in Fig.18. From this figure, it can be seen

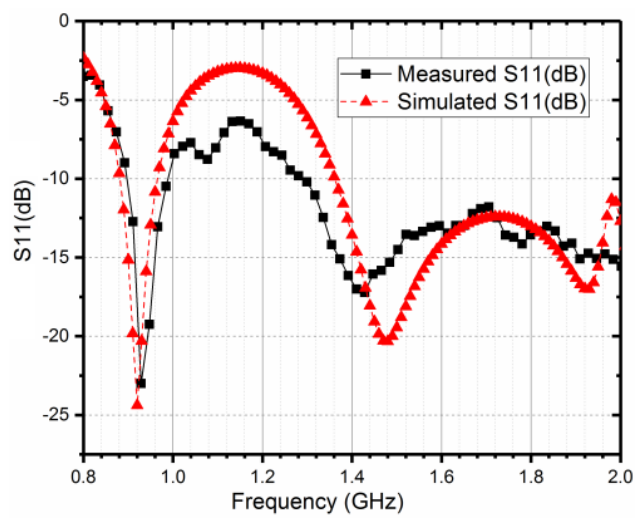

Fig. 18. Simulated and measured reflection coefficient of the wideband dual-band antenna. 


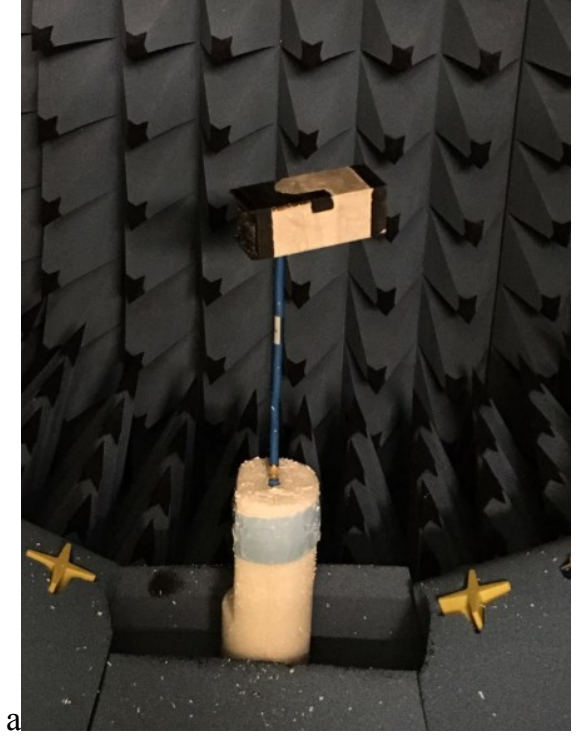

(a)

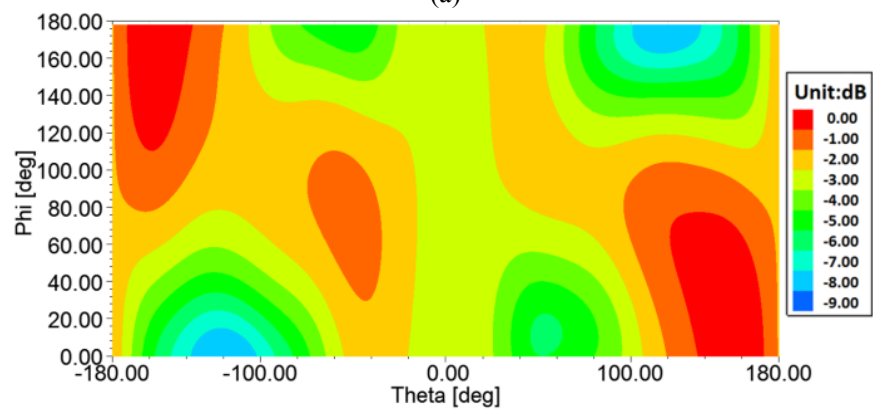

(b)

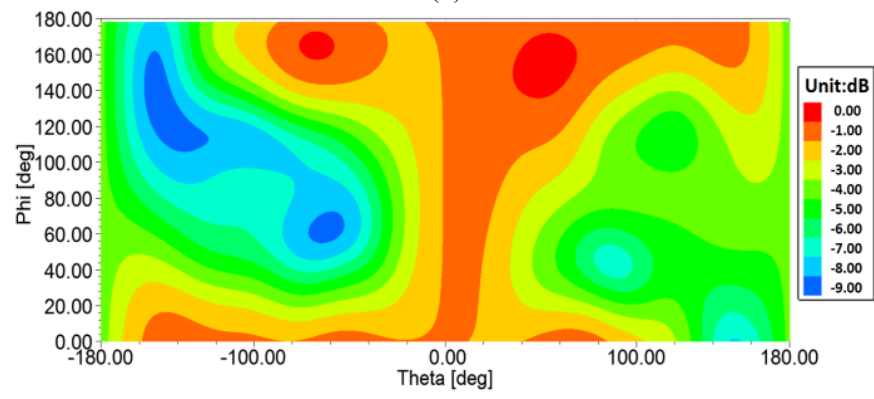

(c)

Fig.19. (a) the antenna inside the anechoic chamber, (b) 2D contour plot for $900 \mathrm{MHz}$ measured radiation pattern, (c) $2 \mathrm{D}$ contour plot for $1800 \mathrm{MHz}$ measured radiation pattern.

that the measured $\mathrm{S}_{11}$ of the wideband antenna is less than -10 $\mathrm{dB}$ for frequencies $886-975 \mathrm{MHz}$ (bandwidth is $9.8 \%$ ) and $1280-1900 \mathrm{MHz}$ (bandwidth is $34 \%$ ). This fulfills the bandwidth requirement for both the GSM bands. Generally, the simulation and measurements are in good agreement, however there are some slight differences that could be due to the loading effect of the SMA connector and cable (which are not part of the simulation model). The radiation pattern of the fabricated antenna has been measured in a Satimo StarLab near-field measurement system, as shown in Fig. 19(a). Fig. 19 (b) and (c) show the normalized 2D contour measured radiation patterns at frequencies of 900 and $1800 \mathrm{MHz}$. The measured maximum gain is 0.90 and $1.71 \mathrm{dBi}$ at frequencies of 900 and $1800 \mathrm{MHz}$ respectively. The gain variation is 8.92 and $9.99 \mathrm{~dB}$ at frequencies of 900 and $1800 \mathrm{MHz}$ respectively.

Table 2 shows a comparison of the simulated and measured results. The simulated and measured results match satisfactorily, except that the measured gain of the antenna is $0.8 \mathrm{~dB}$ less at $900 \mathrm{MHz}$ and $1.5 \mathrm{~dB}$ less at $1800 \mathrm{MHz}$ as compared to the simulated gain. There are two factors responsible for this difference. First, the corner connection of conductive surfaces realized with conductive epoxy does not have conductivity as good as the ideal case in simulations. Second, the roughness of 3D printed surface varies a lot due to layer by layer printing technique employed by the Stratasys 3D printer. Thus, the sidewall of the fabricated package is rougher compared to the flat top and bottom surface. This creates a higher resistance on the antenna segment printed on side wall. Accordingly, antenna efficiency decreases when the operating frequency increases. This means that the antenna has more losses at the frequency of $1800 \mathrm{MHz}$ than at the frequency of $900 \mathrm{MHz}$.

TABLE II

COMPARISON OF SIMULATED AND MEASURED 3D RADIATION PATTERNS

\begin{tabular}{c|c|c|c|c}
\hline \multicolumn{2}{c|}{ Gain } & $\begin{array}{c}\text { Variation } \\
(\mathrm{dB})\end{array}$ & $\begin{array}{c}\text { Maximum } \\
(\mathrm{dBi})\end{array}$ & $\begin{array}{c}\text { Minimum } \\
(\mathrm{dBi})\end{array}$ \\
\hline \hline \multirow{2}{*}{$900 \mathrm{MHz}$} & Simulated & 8.80 & 1.75 & -7.05 \\
\cline { 2 - 5 } & Measured & 8.92 & 0.90 & -7.99 \\
\hline \multirow{2}{*}{$1800 \mathrm{MHz}$} & Simulated & 9.8 & 3.282 & -6.52 \\
\cline { 2 - 5 } & Measured & 9.99 & 1.71 & -8.28 \\
\hline
\end{tabular}

\section{CONCLUSION}

A novel 3D wideband dual-band antenna on package fabricated using low cost screen printing and 3D printing technology is presented for the IoT application. Theoretical conditions to design near isotropic wire antennas on 3D surfaces were derived. These conditions were then used to design a novel 3D wideband dual-band, near isotropic antenna; fabricated on package for miniaturization, using low cost screen printing and 3D printing technology. The fabricated antenna provided $10 \mathrm{~dB}$ impedance bandwidths of $89 \mathrm{MHz}$ and $620 \mathrm{MHz}$ at GSM900 and GSM1800 bands respectively. The achieved bandwidths are wider than the required bandwidths of concerned GSM bands. The antenna maximum gain was measured to be 0.90 and $1.71 \mathrm{dBi}$, with corresponding gain variations of 8.92 and $9.99 \mathrm{~dB}$ at frequencies of 900 and 1800 $\mathrm{MHz}$, respectively. From the comparison table of published work on the topic, it can be seen that the $3 \mathrm{D}$ antenna is amongst the near-isotropic antennas with the smallest electrical dimensions. For future work, this simple theoretical model may be upgraded to include opposite current direction dipoles to cater for more complex designs.

\section{ACKNOWLEDGMENT}

We thank Shuai Yang and Qingle Zhang, for assistance with graphics edition that improved the manuscript. 


\section{REFERENCES}

[1] Luigi Atzoria, Antonio Ierab, Giacomo Morabitoc, "The internet of things: A survey." Computer networks, vol. 54, no. 15, pp.2787-2805, Oct. 2010.

[2] Bartolomeo, M. (2014). "Internet of Things: Science Fiction or Business Fact." A Harvard Business Review Analytic Services Report, Tech. Rep, Harvard Business School Publishing, Apr,2016.

Avaiable: http://www.locate-now.com/tags/Harvard\%20Business\%20Review.pdf

[3] V. H. González-Jaramillo "Tutorial: Internet of Things and the upcoming wireless sensor networks related with the use of big data in mapping services; issues of smart cities", 2016 Third International Conference on eDemocracy \& eGovernment (ICEDEG), pp. 5-6 2016.

[4] Lee. SeokJu, G. Tewolde, Jaerock. Kwon, "Design and implementation of vehicle tracking system using GPS/GSM/GPRS technology and smartphone application", Internet of Things (WF-IoT) 2014 IEEE World Forum on, pp. 353-358, March 2014.

Available: http://ieeexplore.ieee.org/abstract/document/6803187/

[5] P K Rahulkrishna ; R Eshwari ; N J Shree Harsha ; Rajeshwari Hegde. "Design and development of remote load monitoring suitable for non-residential loads through wireless data transmission" Distributed Computing, VLSI, Electrical Circuits and Robotics (DISCOVER), IEEE, Jan, 2017.

Available:

http://ieeexplore.ieee.org/stamp/stamp.jsp?tp=\&arnumber=7806238

[6] WorldTimeZone.com. "GSM Bands information by country". 2016-01-16. Retrieved 2016-02-06. Available: http://www.worldtimezone.com/gsm.html

[7] Rob van der Meulen. (2017, 2). "Gartner Says 8.4 Billion Connected "Things" Will Be in Use in 2017, Up 31 Percent From 2016", Gartner, Inc. Egham, U.K, Feb. 2017.

Available: http://www.gartner.com/newsroom/id/3598917

[8] Benny Kuo, "SiP Technology for Wireless Module Miniaturization". Additional Conferences (Device Packaging, HiTEC, HiTEN, \& CICMT): nol. 2015, no. DPC, pp. 001956-001981, Jan. 2015.

Available: https://doi.org/10.4071/2015DPC-tha21

[9] Charles Chen, "Packaging Breakthrough in Wearable Devices", MediaTek Inc, Taiwan, Sep. 2015.

Available:

http://prod.semicontaiwan.org/en/sites/semicontaiwan.org/files/data15/d ocs/2_5._semicon_taiwan_2015-packaging_breakthrough_in_wearable devices-mediatek-dr._charles_chen.pdf

[10] Douglas S. Thomas and Stanley W. Gilbert, "Costs and Cost Effectiveness of Additive Manufacturing", NIST: National Institute of Standards and Technology, U.S. Department of Commerce, Dec. 2014 Avaiable: http://nvlpubs.nist.gov/nistpubs/SpecialPublications/NIST.SP.1176.pdf

[11] Simon Ford, Mélanie Despeisse, "Additive manufacturing and sustainability: an exploratory study of the advantages and challenges," Journal of Cleaner Production, vol 137, pp 1573-1587, Nov 2016.

[12] C. Cho, H. Choo, I. Park, "Broadband RFID tag antenna with quasi-isotropic radiation pattern", Electron. Lett., vol. 41, no. 20, pp. 1091-1092, Sep. 2005.

[13] J. Ahn, H. Jang, H. Moon, J. W. Lee, and B. Lee, "Inductively Coupled Compact RFID Tag Antenna at $910 \mathrm{MHz}$ With Near-Isotropic Radar Cross-Section (RCS) Patterns," IEEE Antennas and Wireless Propagation Letters, vol. 6, pp. 518-520, Nov. 2007.

[14] C. Cho, H. Choo, I. Park, "Printed symmetric inverted-F antenna with a quasi-isotropic radiation pattern", Microw. Opt. Technol. Lett., vol. 50, no. 4, pp. 927-930, Apr. 2008.

[15] G. Pan, Y. Li, Z. Zhang, and Z. Feng, "Isotropic Radiation From a Compact Planar Antenna Using Two Crossed Dipoles," IEEE Antennas and Wireless Propagation Letters, vol. 11, pp. 1338-1341, Nov. 2012.

[16] C. Deng, Y. Li, Z. Zhang, and Z. Feng, "A wideband isotropic radiated planar antenna using sequential rotated L-shaped monopoles", IEEE Trans. Antennas Propag., vol. 62, no. 3, pp. 1461-1464, Mar. 2014.

[17] Y. M. Pan, K. W. Leung, K. Lu, "Compact quasi-isotropic dielectric resonator antenna with small ground plane", IEEE Trans. Antennas Propag., vol. 62, no. 2, pp. 577-585, Nov. 2014.
[18] J. H. Kim and S. Nam, "A Compact Quasi-Isotropic Antenna Based on Folded Split Ring Resonators," IEEE Antennas and Wireless Propagation Letters, vol. 16, pp. 294-297, 2016.

[19] H. K. Ryu, G. Jung, D. K. Ju, S. Lim, and J. M. Woo, "An Electrically Small Spherical UHF RFID Tag Antenna With Quasi-Isotropic Patterns for Wireless Sensor Networks," IEEE Antennas and Wireless Propagation Letters, vol. 9, pp. 60-62, Feb. 2010.

[20] Kruesi, C. M, Vyas, Rushi J, Tentzeris, Manos M, "Design and development of a novel 3D cubic antenna for wireless sensor networks (WSN) and RFID applications", IEEE Trans. Antennas Propag., vol. 57, no. 10, pp. 3293-3299, Oct. 2009 .

[21] M. F. Farooqui, C. Claudel, A. Shamim, "An inkjet-printed buoyant 3-D Lagrangian sensor for real-time flood monitoring", IEEE Trans. Antennas Propag., vol. 62, no. 6, pp. 3354-3359, Jun. 2014.

[22] C. Deng, Y. Li, Z. Zhang And Z. Feng, "Design Of A Three-Dimensional Folded Slot Antenna With Quasi-Isotropic Radiation Pattern," In Proc. 2015 Ieee International Symposium On Antennas And Propagation \& Usnc/Ursi National Radio Science Meeting, Vancouver, BC, pp. 588-589, Jul. 2015.

[23] M. F. Farooqui, Muhammad Akram Karimi, Khaled Nabil Salama, and Atif Shamim, "3D-Printed Disposable Wireless Sensors with Integrated Microelectronics for Large Area Environmental Monitoring", Adv. Mater. Technol, vol.2, May 2017, Available: https://doi.org/10.1002/admt.201700051.

[24] Kim, J-H., And S. Nam, "Design Of A Compact Dualband Quasi-Isotropic Antenna," Electronics Letters, vol. 53, no.8, pp.515-516, Apr. 2017.

[25] H.C.Huang, X.J. Xu, and Y.X. Ethan Wang, "Dual-Band Isotropic Radiation Patterns from a Printed Electrically Small Loop-Loaded Dipole Antenna", Antennas and Propagation Society International Symposium, 2009. APSURSI '09. IEEE, INSPEC, Jul. 2009

[26] S. Shamsinejad, F. De Flaviis and P. Mousavi, "Microstrip-Fed 3-D Folded Slot Antenna on Cubic Structure," IEEE Antennas and Wireless Propagation Letters, vol. 15, pp. 1081-1084, Oct. 2016.

[27] S. Zhen and A. Shamim,"A 3D Printed Dual GSM Band Near Isotropic On Package Antenna", in Proc. of IEEE International Symposium On Antennas And Propagation \& Usnc/Ursi National Radio Science Meeting, San Diego, CA, USA, July 2017.

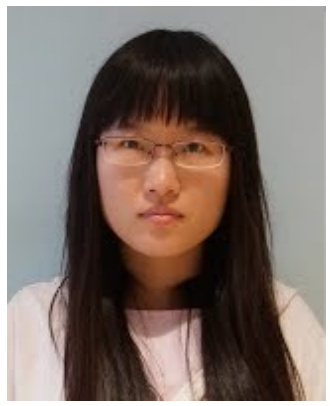

ZHEN SU (M'16) was born in Hebei, China. She received the B.Sc, School of Information Science and Engineering, Jinan, China in 2011, and M.Sc. degree in Integrated Circuits Design Engineering (ICDE) from Hong Kong University of Science and Technology, Hong Kong in 2012.

From 2013 till now, she is a Ph.D. candidate working in IMPACT Lab, King Abdullah University of Science and Technology, Saudi Arabia.

Her research interests include antennas with near isotropic patterns, antenna-on-package designs, and multiple antennas system designs.

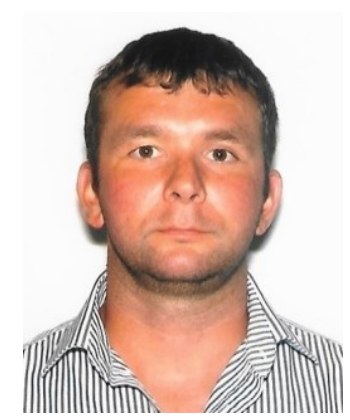

Kirill Klionovski received the Engineer (with Hons.) degree in electrical engineering from the Moscow Aviation Institute, Moscow, Russia, in 2010, and the Candidate of Sciences degree (is equivalent to 
Ph.D.) in radiophysics from the Kotel'nikov Institute of Radio-engineering and Electronics, Russian Academy of Sciences, Moscow, in 2015.

His current research interests include the antenna pattern synthesis theory.

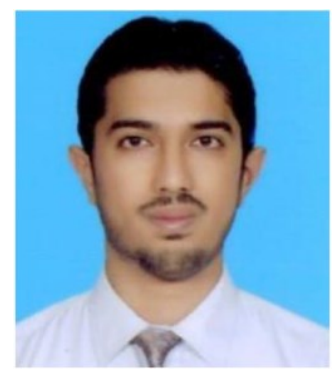

Rana Muhammad Bilal was born in Karachi, Pakistan in 1988. He received BS Electronic engineering degree from GIK Institute of Science and Technology, Pakistan in 2009 and MS Electrical engineering degree from National University of Science and Technology, Pakistan in 2014.

From 2012 to 2014, he was a visiting researcher at King Abdullah University of Science and Technology, where he is currently working as Project consultant. His Research interests include integrated indoor/outdoor localization, embedded system design, location aware applications and IoT.

Bilal was a recipient of indigenous scholarship at National University of science and technology, as well as senior year design project award at GIK Institute. He has also received several funding awards for commercialization of his research at King Abdullah University of Science and Technology.

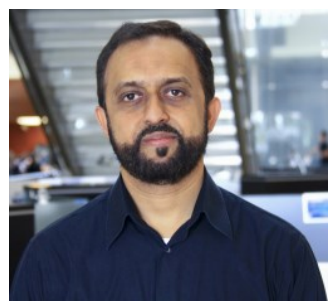

Atif Shamim (SM'13) received his M.A.Sc. and Ph.D degrees in electrical engineering at Carleton University, Canada in 2004 and 2009 respectively. He was an NSERC Alexander Graham Bell Graduate scholar at Carleton University from 2007 till 2009 and an NSERC postdoctoral Fellow in 2009-2010 at Royal Military College Canada and KAUST. In August 2010, he joined the Electrical Engineering Program at KAUST, where he is currently an Associate Professor and principal investigator of IMPACT Lab. He was an invited researcher at the VTT Micro-modules Research Center (Oulu, Finland) in 2006. Dr. Shamim was the recipient of the best paper prize at the European Microwave Association Conference in 2008. He was given the Ottawa Centre of Research Innovation (OCRI) Researcher of the Year 2008 Award in Canada. His work on Wireless Dosimeter won the ITAC SMC Award at Canadian Microelectronics Corporation TEXPO in 2007. Prof. Shamim's students won the Best Paper Prize (3rd position) in IEEE IMS 2016 and (1st position) in IEEE MECAP 2016. Prof. Shamim also won numerous business-related awards, including the 1st prize in Canada's national business plan competition and was selected for OCRI Entrepreneur of the year award in 2010. He is an author/co-author of over 180 international publications and an inventor on 20 patents. His research interests are in innovative antenna designs and their integration strategies with circuits and sensors for flexible and wearable wireless sensing systems through a combination of CMOS and additive manufacturing technologies. Dr. Shamim is a Senior Member of IEEE and serves on the editorial board of IEEE Transactions on Antennas and Propagation. 